\title{
Surface water quality in palm oil plantation
}

\author{
Nur Syakira Che Nadzi, Mohd Zahari Abdullah*, Fazrul Razman Sulaiman \\ Faculty of Applied Sciences, Universiti Teknologi MARA Pahang, Malaysia. 26400 Bandar Tun Razak Jengka, Pahang, Malaysia \\ *Corresponding author: umizah@pahang.uitm.edu.my
}

\section{Article history}

Submitted 27 February 2018

Revised 28 March 2018

Accepted 21 May 2018

Published Online 4 February 2019

\begin{abstract}
River water that is directly connected to palm oil plantation activities has been analysed for concentration of $\mathrm{Zn}, \mathrm{Pb}$ and $\mathrm{Cu}$, as well as its physicochemical parameters. The samples were collected from 12 sampling points along the river in which located in Jerantut District in Pahang, Malaysia. The metal concentration was determined using Inductively Coupled Plasma Optical Emission Spectroscopy (ICP - OES) in triplicates after undergoing through chemical treatment. Six physicochemical parameters; temperature, salinity, dissolved oxygen (DO), $\mathrm{pH}$, total dissolved solids (TDS) and specific conductance were measured in-situ. The average water temperature was recorded at $28.01^{\circ} \mathrm{C}, 0.02 \mathrm{ppt}$ for salinity, $0.13 \mathrm{mg} \mathrm{L}^{-1}$ for $\mathrm{DO}, 7.90$ for $\mathrm{pH}, 0.031 \mathrm{mg} \mathrm{L}^{-1}$ for TDS and $51.8 \mu \mathrm{S} \mathrm{cm}^{-1}$ for conductivity. The mean concentrations of the studied metals were observed to be lower than the standard level proposed by WHO and USEPA for drinking water and ecosystem safety except for $\mathrm{Pb}$. The contamination factor (CF) for all elements was indicated at the uncontaminated level for all sampling points. Generally, the study found that the river was not contaminated with the studied pollutants and the nearby plantation activities did not seriously affect the quality of the studied river.
\end{abstract}

Keywords: River water, heavy metal, palm oil plantation, contamination factor

\section{INTRODUCTION}

The good quality of water is further decreasing all over the world (Robert \& Sadler, 2008). Some factors that affect water quality are urban development, industrial growth and plantation activities (Mustapha \& Getso, 2014). The universal solvent is one of the unique properties of water, thus it is able to dissolve a large number of different chemical compounds either organic or inorganic. Surface water contamination especially river becomes a current issue as the river water is easier to be polluted. The river receives various outfalls of domestic effluents that contained various types of undesired matter including the dissolved chemicals.

The Pahang river begins to flow in the south-east in Lipis and Jerantut districts; then heads towards south directions to Temerloh and turns eastward at Mengkarak in the central south of Pahang. This river flows through Pekan town near the coast before meeting the final destination, the South China Sea. The river traverses through almost all districts in Pahang, by supplying water, facilitating fishing and farming activities, providing another means of transportation and even fueling tourism and recreational activities. The eastern part of the Malaysian Peninsula is affected by rainy season (monsoon) in between mid-October and the end of March every year. During the monsoon periods, it can be raining for days. Rainwater can wash off soil and debris from the land into the rivers. As the number two producer of palm oil in the world, many of the river pollutions in Malaysia are contributed by the oil palm estates. Logging and clearing land activities for oil palm plantations also lead to soil erosion and subsequently rivers are filled with sedimentation. The unrestricted use of chemicals in fertilizers and pesticides is also adversely affected river water quality (Aktar et al., 2009; Agrawal et al, 2010). Some studies showed that most of the rivers and lakes were affected by agricultural non-point source (NPS) pollution (USEPA, 2014). NPS pollution has been created by many diffuse sources such as land runoff, precipitation, atmospheric deposition, drainage, seepage or hydrologic modification. Pollutants carried by runoff were then deposited into the nearby surface water.

Oil palm plantations make up $77 \%$ of agricultural land in Malaysia. Fertilizers, pesticides, and rodenticides are some of the agrochemical pollutants that regularly used by planters in palm oil production. The application of harmful herbicides and pesticides straightly affects human health. During heavy rains, effluents from palm oil mill that are contaminated usually overflowing into the river (Cheng Hai, 2002). Excessive use of agrochemicals and dangerous agricultural habits lead to air, soil, and water pollution. The application of toxic agrochemicals such as phosphate fertilizer can contaminate the nearby surface water with some heavy metals, organic and inorganic matters. These pollutants present in water generally in a trace amount and subsequently cannot be seen or tasted. Hence, their dangerous effects do not manifest in human for several years. Natural resources such as soil, water and air should be preserved for the benefit of all, especially for the future generation. Currently, the pollution of the agricultural site is one of the serious environmental concerns. Lack of fertilizing regulations may cause severe environmental damage and exposure of toxic chemicals to the surrounding.

Pesticides contain different concentrations of heavy metals which are available in considerable amount in the environment once they are being used. Some heavy metals that are generally related to the fertilizer and pesticide include $\mathrm{As}, \mathrm{Al}, \mathrm{Cd}, \mathrm{Pb}, \mathrm{Mn}, \mathrm{Cu}$ and $\mathrm{Zn}$ (Mirsal, 2008). Hence, the objective of this study was to analyze the 
physicochemical parameters and the concentration of $\mathrm{Zn}, \mathrm{Pb}$ and $\mathrm{Cu}$ contained in the palm oil plantation water and to evaluate the contamination level of the studied metals for the benefit of the local residents that consumes the water for their daily activities.

\section{MATERIALS AND METHOD}

\section{Sampling site}

The water samples were collected from 12 sampling points along the Pahang River near Jerantut Ferry with latitude N $3^{\circ} 07^{\prime \prime}$ and longitude $\mathrm{E} 102^{\circ} 82^{\prime}$ " which covered $1.2 \mathrm{~km}$ in distance. The river is considered important for the local residents for their fishing and planting activities. The river flows along the plantation area for both left and right sides.

\section{Sample collection}

Surface water samples have been collected in August of 2016. Sampling was done to suit the local condition especially on the topography of the sampling areas and the number of surface water sample required based on a previous study (Varol \& Sen, 2012). Samples were collected from upstream to downstream of the river which around $100 \mathrm{~m}$ in distance. Water samples were collected at the level of approximately $0-20 \mathrm{~cm}$ of the surface river by using pretreatment polyethylene bottles. Samples for heavy metal analysis were acidified and put in an ice box prior to transportation to the lab. For the in-situ parameters, samples were measured immediately after collection.

\section{Physical pretreatment and analysis}

Water samples were filtered for any undesirable materials by using Whatman type filter paper. The concentrations of selected metals included $\mathrm{Cu}, \mathrm{Al}$, and $\mathrm{Pb}$ were analysed using Inductively Coupled Plasma Optical Emission Spectrometry, ICP OES (5100 Agilent Technologies). About $10 \%$ of duplicated samples and surface water standard reference materials CRM 7303 - Lake Sediment were prepared and analysed with the same procedure and reagents for the quality assurance and control (QA/QC) (Abdullah, Ismail, \& Mahammad, 2014).

\section{Quality control}

The laboratory quality control was assured by implementing the standard operating procedures for standards calibration, reagent blanks, recovery of known additions and replication in order to gain valid data. All analyses were carried out in duplicate, and the results were presented as the mean and standard deviation.

\section{RESULTS AND DISCUSSION}

\section{Water quality parameter}

Table 1 shows the mean value of physicochemical parameters for water samples that have been collected at different points along the stretch of the river. These parameters were important because they gave an indication of the water quality level and thus, reflecting the sustainability of aquatic life in the river.

Table 1 Mean value of selected physicochemical parameters in Pahang River near Jerantut Ferry.

\begin{tabular}{cc}
\hline Parameters & Average value \pm \\
SD \\
\hline Temperature $\left({ }^{\circ} \mathrm{C}\right)$ & $27.99 \pm 0.67$ \\
$\mathrm{pH}$ & $7.42 \pm 0.35$ \\
Dissolved Oxygen $(\mathrm{D} 0)(\mathrm{mg} \mathrm{L}-1)$ & $1.31 \pm 0.01$ \\
Conductivity $(\mu \mathrm{S} \mathrm{cm}-1)$ & $52.12 \pm 0.79$ \\
Salinity (ppt) & $0.22 \pm 0.04$ \\
Total Dissolved Solid (TDS) (mg L- & $32.03 \pm 0.30$ \\
1) & \\
\hline
\end{tabular}

The temperature of the river water sample was varied between 26.05 and $30.00^{\circ} \mathrm{C}$ with an average $27.99^{\circ} \mathrm{C}$. Temperature is one of the most essential water parameters. Perhaps surrounding activities such as chemical discharged into the river water might increase the temperature. Temperature influences the growth and activity of aquatic life. Thus, the rise in water temperature could decrease the concentration of oxygen, resulted in the increase of the chemical and biochemical reactions in the water body. If the water temperature was increased, the distribution of aquatic species in the water body might also be affected (El-Morhit \& Mouhir, 2014).

The $\mathrm{pH}$ is another important water quality parameter. According to El-Morhit and Mouhir (2014), the $\mathrm{pH}$ of the water indicated for the balance between carbonates and bicarbonates. The $\mathrm{pH}$ value perhaps influenced by the balance of respiratory and photosynthesis activities, the carbon dioxide concentration, the geological characteristics of the stream and discharge of sewage (El-Morhit \& Mouhir, 2014). Water $\mathrm{pH}$ could be decreased due to mineralization of organic matter (Morhit, Fekhaoui, El Morhit, \& Yahyaoui, 2013). In this study, $\mathrm{pH}$ values were varied between 6.78 and 8.02 with an average of 7.42. The variation was expected to be influenced by the buffering effect of bicarbonate ions, indicating the poor portability of the water.

The conductivity relatively indicates the variation of ionic concentration in water. It may suggest the degree of mineralization of the surface water. Water conductivity value may change if there is an increase in temperatures (Wang et al., 2006). Natural water can act as a solvent for a considerable number of solutes, either completely or partially ionized. Alkalis, chlorides, sulphides and carbonate compounds are some examples of dissolved salts that form ionic component in water. In this study, the average conductivity of the river was $52.12 \mu \mathrm{S} / \mathrm{cm}$ which within the range of 50.65 to 53.98 $\mu \mathrm{S} / \mathrm{cm}$. The low water conductivity clearly showed low enrichment of organic conducting species from the surrounding effluents (Mariam \& Florence, 2014)

Total dissolved solids (TDS) represent dissolved matters such as salts, organic matter, and inorganic matter in water. Extreme TDS value can changes the composition of water, leading to toxication of the aquatic life. Aquatic ecosystems can tolerate TDS levels of about $1000 \mathrm{mg} / \mathrm{l}$ (Boyd, 1999). The present study, however, showed the mean value of TDS that was varied from 29.04 to $43.15 \mathrm{mg} / \mathrm{l}$ with an average of $32.03 \mathrm{mg} / \mathrm{l}$ in which within the acceptable level.

Dissolved oxygen (DO) in water is essential for aquatic life. Variation of DO level is depended on the temperature, season, the depth of water body and the water flow rate. DO in this study was observed to be in ranges from 1.0 to $1.6 \mathrm{mg} / \mathrm{l}$ with an average of 1.31 $\mathrm{mg} / \mathrm{l}$. The DO concentration in range 4 to $11 \mathrm{mg} / \mathrm{l}$ is considered as good for aquatic animals and most stream fishes (APPA,1992). The low DO concentration observed in this study could be related to the addition of fertilizers, sewage, changes in the flow rate of water and the addition of chemicals from the surrounding plantation activities. Anaerobic decomposition of organic matter could happen due to deficiency of dissolved oxygen (Himangshu, Das, \& Nanda, 2012).

Salinity indicates the percentage of chloride in water. It is important to aquatic organisms since they have varying abilities to survive at different salinity levels. For freshwater organisms, the salinity level should be below 1 ppt meanwhile saltwater organisms stay alive in $40 \mathrm{ppt}$. The salinity levels recorded in this study were in the range of $0.12-0.32 \mathrm{ppt}(120-320 \mathrm{mg} / \mathrm{l})$ with the average of $0.22 \mathrm{ppt}(220 \mathrm{mg} / \mathrm{l})$. The values indicated that the salinity of the river would not give any harmful effect to its aquatic organisms.

\section{Metal concentration}

The concentrations of the studied heavy metals of the river water were presented in Table 2 .

The mean concentration of the metals was followed the increasing order of: $\mathrm{Cu}<\mathrm{Pb}<\mathrm{Zn}$. The mean concentration of $\mathrm{Cu}$ in water was observed at $10.4 \mu \mathrm{g} / \mathrm{L}$, which was slightly higher than the USEPA standard level but much lower compared to the standard level by WHO for drinking water. One of the sources that might pollute the river with $\mathrm{Cu}$ was fertilizing activity. Application of agrochemical pollutants like fungicides on crops would rise up the copper concentration (Mico, Peris, Recatala, \& Sanchez, 2007). Another possible source was primarily contributed by agricultural practices where copper was being used as a micronutrient requirement for palm oil cultivation. 
The mean concentration of $\mathrm{Pb}$ was observed at $18.8 \mu \mathrm{g} / \mathrm{L}$ which was higher than the values suggested by WHO and USEPA for standard levels. Lead is one of the major heavy metal in fertilizer (Savci, 2012). The low concentration of $\mathrm{Pb}$ obtained in this study might be due to high agronomic practices like fertilization. Lead is not a necessary element for plant development (Osobamiro \& Adewuyi, 2015).

Table 2 The concentrations of $\mathrm{Zn}, \mathrm{Pb}$ and $\mathrm{Cu}$ along Pahang River near Jerantut Ferry (Average of two samples at each sampling station).

\begin{tabular}{cccc}
\hline \multirow{2}{*}{ Sampling Point } & \multicolumn{3}{c}{ Heavy metal concentrations $(\boldsymbol{\mu g} / \mathbf{L})$} \\
\cline { 2 - 4 } & $\mathbf{Z n}$ & $\mathbf{P b}$ & $\mathbf{C u}$ \\
\hline 1 & 53.3 & 20.1 & 5.2 \\
2 & 41.2 & 10.2 & 25.3 \\
3 & 40.3 & 10.2 & 10.2 \\
4 & 31.2 & 15.1 & 5.3 \\
5 & 40.2 & 10.4 & 25.4 \\
6 & 60.3 & 10.3 & 10.2 \\
7 & 40.5 & 20.4 & 10.1 \\
8 & 40.1 & 30.3 & 10.1 \\
9 & 50.1 & 35.3 & 10.2 \\
10 & 50.4 & 30.7 & 10.4 \\
11 & 30.2 & 15.4 & 5.4 \\
12 & 40.3 & 20.4 & 10.1 \\
Mean Concentration & 79.7 & 19.1 & 10.4 \\
Mean CF & 0.61 & 2.72 & 0.58 \\
(WHO, 1996) & 3.00 & 10.0 & 50.0 \\
(USEPA, 2014) & 120 & 2.5 & 9.0 \\
\hline
\end{tabular}

USEPA - United State environmental protection agencies; WHO World Health Organization (for drinking water).

The mean concentration of $\mathrm{Zn}$ was observed to be the highest among the three metals with a value of $79.7 \mu \mathrm{g} / \mathrm{L}$. The observed concentration of $\mathrm{Zn}$ in this study was much lower than the USEPA standard level but much higher than the level set by WHO. The high concentration of $\mathrm{Zn}$ might be attributed to the domestic activities especially related to the plantation process, in which the zinc oxide was being used as a white pigment in rubber and zinc carbamates were being used as pesticides (Elinder 1986). The correlation coefficients of $\mathrm{Zn} / \mathrm{Pb}, \mathrm{Zn} / \mathrm{Cu}$ and $\mathrm{Pb} / \mathrm{Cu}$ were found as $0.208,0.004$ and -0.350 respectively. The low correlation level among these metals clearly indicated that the studied metals were possibly contributed by the different sources.

\section{Assessments of metal contamination}

The contamination factor (CF) was used to estimate the metal contamination trends and to compare the measured parameters. The $\mathrm{CF}$ in this study was calculated based on the following equation

$$
C F=C m / B m
$$

where $\mathrm{CF}$ is contamination factor of the element of interest; $\mathrm{Bm}$ is background concentration in this study; and $\mathrm{Cm}$ is the concentration of the element in the sample. Contamination factor can be divided into six categories which include: $<1$ no contamination; $1-2=$ suspected; $2-3.5$ slight; $3.5-8$ moderate; $8-27$ severe; above $27=$ very high contamination (Hakanson, 1980).

The mean contamination factor (CF) was determined as 0.61 , 2.72 and 0.58 for $\mathrm{Zn}, \mathrm{Pb}$ and $\mathrm{Cu}$ respectively. In general, the $\mathrm{CF}$ suggested no contamination of $\mathrm{Cu}$ and $\mathrm{Zn}$. However, $\mathrm{Pb}$ was observed at a slightly contaminated level. The low enrichment of the studied metals of $\mathrm{Zn}, \mathrm{Pb}$ and $\mathrm{Cu}$ in the river clearly indicated that the least effects of various agricultural practices in the area to the nearby river such as irrigation, use of fertilizers, and organic manure.

\section{CONCLUSION}

Poor water quality can impose a health risk for people and damage to the aquatic ecosystem. This study suggested some physicochemical pollution in the water body although some values of these parameters were within an acceptable range. The study also revealed that the water was not safe for drinking but almost good for aquatic life and for irrigation purpose in some extents. The study location was not seriously contaminated with $\mathrm{Zn}, \mathrm{Pb}$ and $\mathrm{Cu}$. The obtained concentrations of metals were lower than the values suggested by USEPA and WHO except for $\mathrm{Pb}$. The more comprehensive monitoring program is necessary in order to protect river water from any types of pollutants and sustain the river water quality.

\section{ACKNOWLEDGEMENT}

The authors would like to thank the Ministry of Higher Education of Malaysia (KPT) and Research Management Unit, UiTM for the financial supports (FRGS Grant) and all individuals for their assistance and recommendations.

\section{REFERENCE}

Abdullah, M. Z., Ismail, A., Mahammad, N. I. (2014). Statistical analysis Of heavy metal concentration in moss and soil as indicator of industrial pollution. International Journal of Science, Environment and Technology, 3(3), 762-775.

Agrawal, A., Pandey, R. S., Sharma, B. (2010). Water pollution with special reference to pesticide contamination in India. Journal of Water Resource and Protection, 2(5), 432-448.

Aktar, M. W., Sengupta, D., Chowdhury, A. (2009). Impact of pesticides use in agriculture: Their benefits and hazards. Interdisciplinary Toxicology 2(1), 1-12.

American Public Health Association (APHA). (1992). Standard methods for the examination of water and wastewater. $18^{\text {th }}$ ed. Washington, DC: APHA

Boyd, E. C. (1999). Water Quality: An Introduction. The Netherlands: Kluwer Academic Publishers Group.

Igwe, J. C., Onyegbado, C. C. (2007). A review of Palm oil mill effluent (Pome) water treatment. Global Journal of Environmental Research. 1(2): 54-62.

El-Morhit, M., Mouhir, L. (2014). Study of physico-chemical parameters of water in the Loukkos river estuary (Larache, Morocco). Environmental Systems Research, 3(17), 1-9.

Elinder, C. (1986). Zinc. In Friberg, L, Nordberg, G. F., Vouk, V. B. (Eds.), Handbook on the Toxicology of Metals, (Vol. $2^{\text {nd }} \mathrm{ed}$, pp. 664-679). Amsterdam: Elsevier Science Publishers.

Hakanson, L. (1980). Ecological risk index for aquatic pollution control, a sedimentological approach. Water Resource, 14, 975-1001.

Himangshu, S. M., Das, A., Nanda, A. K. (2012). Study of some physicochemical water quality parameters of Karola River, West Bengal An attempt to estimate pollution status. International Journal of Environmental Protection, 8, 16-22.

Mariam, I. H., Florence, A. M. J. (2014). Nutrient and phytoplankton dynamics along the ocean road sewage discharge channel, Dar es Salaam, Tanzania. Journal of Ecosystems, 2014, 1-8.

Mico, C., Peris, M., Recatala, L., Sanchez, J. (2007). Baseline values for heavy metals in agricultural soils in an European Mediterranean region. Science of the Total Environment, 378(1-2), 13-17.

Mirsal, I. A. (2008). Soil Pollution, Origin, Monitoring and Remediation $\left(^{\text {nd }}\right.$ ed.). Berlin: Springer.

Morhit, M. A., Fekhaoui, A., El Morhit, P., Yahyaoui, A. (2013). Hydrochemical characteristics and metallic quality in fish in the Loukkos river estuary of Morocco. Journal of Materials and Environmental Science, 4(6), 893-904.

Mustapha, A., \& Getso, B. U. (2014). Sources and pathway of environmental pollutants into surface water resources: A review. Journal of Environments, 1(2), 54-59.

Osobamiro, M. T., Adewuyi, G. O. (2015). Levels of heavy metals in the soil: Effects of season, agronomic practice and soil geology. Journal Agriculutral Chemistry and Environment, 4, 109-117.

Robert, G. E., Sadler, E. J. (2008). Methods and technologies to improve efficiency of water use. Water Resources Research, 44, 1-15.

Savci, S. (2012). An agricultural pollutant: Chemical fertilizer. International Journal of Environmental Science and Development, 3(1), 11-14.

United States Environmental Protection Agency (US EPA). (2014). Climate Change Indicators in the United States, third edition. EPA 430-R-14-004. www.epa.gov/ climatechange/ indicators.

Varol, M., Sen, B. (2012). Assessment of nutrient and heavy metal contamination in surface water and sediments of the upper Tigris River, Turkey. Catena, 92, 1-10.

Wang, D., Mookherjee, M., Xu, Y., Karato, S. (2006). The effect of water on the electrical conductivity of olivine. Nature, 443, 977-980.

World Health Organisation (WHO). (1996). Zinc in Drinking Water. Guidelines for drinking-water quality, 2nd ed. Vol. 2. 